certain soil problems, we were glad to have the opportunity of visiting the Vernadsky Laboratory of Geochemical Problems of the Academy. In this institute, under A. P. Vinogradov, there is going on a great amount of work on the distribution of the minor elements in soils and biological materials. The laboratories are very well equipped with modern physical apparatus, including X-ray spectrographs and recording photometers. One of the principal tasks of the institute is the construction of a map showing the geochemical provinces of the U.S.S.R., and considerable attention is being paid to the relation of endemic diseases and minor element distribution.

\title{
THE INFERIORITY COMPLEX AND THE PARANOID TENDENCY: WITH A BRIEF REFERENCE TO NAZI PSYCHOLOGY*
}

\author{
BY DR. WILLIAM BROWN \\ University of Oxford
}

$\mathrm{T}$ HE subject-matter of this essay has a very important bearing upon the world problems of the present day. The popular conception of the inferiority complex has become a scandal in modern psychology. It is a term easy to use, and it has suffered a fate somewhat similar to that of the word 'idea' in John Locke's 'Essay Concerning Human Understanding" (1690). In that work he used the term 'idea' in a special sense, as illustrated in his definition ("Essay", Bk. I, Chap. i, § 8) : "whatsoever is the object of the understanding when a man thinks". The general line of his argument was "the new way of ideas", of which Stillingfleet spokedisapprovingly - on the first appearance of the "Essay". But Locke himself used the word in several different ways, and very soon it got into the general vocabulary of English literature in a large number of senses. That is an aftermath of Locke's important work.

\section{Misuse of the Term 'Inferiority Complex'}

It seems fated that the term 'inferiority complex', which had a fairly definite meaning when originally developed by the late Dr. Alfred Adler and some of his followers, should come into general use in so vague a form as to be of practically no value for the man of science. It is misleading because it gives an air of profundity to statements which are extremely elementary and superficial. Here I am not criticizing Adler's general position in the succession of the great medical psychologists, Sigmund Freud and C. G. Jung. We have much to learn from all three of them. Each has a message and to each belongs much solid research work on the mind. But it is a little unfortunate that Adler's position in psychology should be so much easier to understand at first blush than the systems of Freud and Jung. The result has been that it has attracted popular thought and opinion because of its simplicity, and has discouraged deeper consideration of these problems by the general educated public.

I am not at all sure that it was Alfred Adler himself who first used the term 'inferiority complex'. He spoke first of 'organ-inferiority' (Minderwertigkeit von Organen), a physical deficiency to which individuals react physiologically and psychologically in different compensatory ways. Adler's book on 'The Neurotic Constitution" $\uparrow$ contains much fundamental discussion along this line of thought. But when he came to deal more closely with the mind and its reactions, some-

- Based on a lecture delivered at Christ Church, Oxford, on November 25,1944 .

† Translation by B. Glueck and J. E. Lind (New. York: Moffat, Yard and Co., 1917). one or other-I do not know who-introduced the term 'complex' in popularizing his psychological point of view: a word much used in those days, starting with Freud's 'CEdipus complex', and Jung's use of the term as meaning a repressed system of ideas with an emotional colouring, revealing itself in consciousness in a disguised form. So the word became attached to inferiority-Minderwertigkeit. This 'feeling of inferiority', Minderwertigkeitsgefühl, which in some respects we all share in one direction or another, undergoes (through repression) transformation in various ways to become an 'inferiority complex'--in other words, the total mind reacts to the feeling of inferiority, with all manner of results in thinking, feeling and behaviour.

Every one of us is, of course, inferior in some direction or other. No one can do everything well. A man may be a genius in some directions, but a dunce in others. We have to accept our limitations, recognize them for what they are, realize that nothing can be done about it, and push on with those lines of activity in which we are outstanding, or relatively normal and efficient. If we attach an excessive value to certain abilities and powers, artistic or intellectual or whatever they may be, which we ourselves do not possess to any great extent, but wish we did, we may come to imagine ourselves possessing them in a greater degree than we do, so that a certain distortion appears in our mental outlook. We are no longer single-minded, honest-to-goodness people moving forward with all the forces at our disposal; we begin to pretend to be something which we are not, and we deceive ourselves, and perhaps-which is less likely-deceive others. Man is the only animal capable of deceiving himself, and that self-deception accounts for many of the troubles of the world. We do not like to admit our inferiority even to ourselves, and in hiding it, we develop an inferiority complex. We pass from a 'feeling of inferiority', which is straightforward and unblamable, to develop an 'inferiority complex', a reaction which is not straightforward, which is a sin against our own nature, by pretending to be what we are not, and putting up a mere facade in the sight of the world.

\section{Compensation and Over-compensation}

In trying to hide our inferiority from ourselves we may over-compensate. There is an automatic tendency in any organism to compensate for deficiency, but it is easy to compensate to excess. A familiar example is the youth who is by nature diffident, retreating, and shy; and who, as a result of overcompensation, develops a blustering and swaggering attitude. Again, many people compensate for lack 
of success by imagining it, and as they give way to their phantasies and day-dreams, they come at last to believe that they have the power or to pretend that they have it, while at the same time retreating from any actual test.

An alternative reaction is just to fall ill, when confronted with a real test. The person concerned may suffer with headache, anxiety, depression, sleeplessness, loss of appetite-general symptoms which cannot in his case he explained in terms of physical disease, but are quickly understood by one who knows the real situation. There are these various possible reactions to the feeling of inferiority, and they are evidence of the existence of the complex-a complex involving self-deception, which nevertheless is not quite complete. The term should be used only to describe a distorted conscious reaction in the mind of the individual to a repressed or rejected feeling of inferiority.

The general public, including some journalists, in seizing upon this term, have used it almost invariably in the wrong sense. They talk of 'inferiority complex' when what they have in mind is simply the fully conscious awareness by an individual of his inferiority in some direction or other-a very different thing. But although the inferiority complex is a further stage of complication in the mind, a stage beyond the clear consciousness of inadequacy, a disguise, a mask, a distortion, a camouflage, it is a very superficial form of disguise. The inferiority complexusing the term in its exact sense-is not very important and is easily dealt with. Those, for example, who wish to become psychotherapists, and get themselves analysed in order, so to speak, to have a mental cleansing before starting work, get rid of their inferiority complexes fairly quickly in the course of their analysis. The inferiority complex is at a relatively superficial level of the mind, and the more unconscious levels have yet to be reached.

\section{Deeper Analysis}

I found it not surprising, when in 1926 I came to know Alfred Adler personally, that he did not consider it necessary to carry out really deep and prolonged analyses, even in special cases. I think that that attitude was unfortunate for the Adlerian development of psychology. Adler stated that he could generally sum up his patient in one or two interviews - an insult, really, to human nature to suggest that it can be so casually explored. To go deeper one must have recourse to Sigmund Freud's analytical method and general explanatory system (whatever one may think of his central theory), with its conception of libido, sexual energy in its widest sense, which supports and sustains the world, the "Epws of Greek philosophy and myth, rooted in the physical, and yet transcending this in æsthetic and spiritual insight and inspiration.

Directly the libido is brought in, we reach a much deeper level of the mind. The libido is relatively impersonal, as contrasted with the organized ego; it is the $I d$ (das $E s)$, it is something below and beyond the individual and for the most part unconscious. The individual, as Jung said, is rather like a frail craft floating on the turbulent waters of the unconscious. Jung took the libido in a wider sense than that of Freud, as meaning instinctive energy in general, somewhat, though not exactly, like the élan vital of Bergson's philosophy. Using the conception in the narrower, Freudian sense, we find reactions of a complex nature, where love may be linked up at a primitive level with aggressiveness or destructiveness, with sadism as a result. Later, mental reactions to this sadism may produce an obsessed type of personality. At the level of the inferiority complex there is just wounded self-love, self-centredness. Self-love or narcissism, according to the Freudian theory, is a fixation of libido upon oneself. But it should be projected upon others and should result in the linking up of individuals in the group, sustaining the loyalty of the individuals of the group to a leader, where a leader is involved, and making the individuals "members one of another", to use the Pauline phrase.

This love or libido in its original form is both homosexual and heterosexual. It can be felt for individuals of the same as well as for those of the opposite sex. Freud held that there is a homosexual constituent of the libido in everyone, which normally becomes sublimated before and at adolescence. It emerges in feelings of friendship, good-fellowship and group loyalty. It is expressed in that beautiful lament of David for Jonathan (Samuel II, Ch. i, \$§ 17-27), and in Shelley's "Adonais", his elegy on the death of Keats. On the heterosexual side, however, love or Eros is more deeply held, because here it has a physical function to serve, that of handing on the torch of life to the next generation, but it too becomes spiritualized in its higher forms. There is such a thing as "a love passing the love of women", and, higher still, that Amor intellectualis Dei which Spinoza took as the goal and guiding star of his system of philosophy.

\section{The Paranoid Tendency}

This leads me to the consideration of a mental tendency which in my research work in medical psychology I am learning to regard as of great importance, namely, the paranoid tendency. It is rooted in unconscious mental activity, at a deeper level than that supporting an inferiority complex, in relation to the development of the super-ego (the primitive psychological basis of conscience) by the processes of introjection and projection. This deeper root is its relation to the libido, mainly though not exclusively to the homosexual element in it. I am not yet sure to what extent the paranoid tendency may be linked up with heterosexual libido; it may be not infrequently so. But in full-blown paranoia, where the paranoid tendency appears in, as it were, pure culture, repressed homosexuality seems to be invariably present and the main cause of the delusional system (Wahnsystem).

This condition of paranoia, which has a hereditary basis, is not so rare a mental illness as the few cases seen in mental hospitals would suggest. It is more a general type of character and personality than a special mental disease or psychosis, with fanaticism as an outstanding characteristic. The paranoiac is born rather than made, and if his family history be inquired into there will generally be found some evidence of the same tendency in previous generations, showing itself sporadically in the family tree. The trouble about the paranoiac is that he is detected and dealt with only when he becomes an evident danger to himself and to others. It is then that he is placed in a mental hospital. But few paranoiacs are found in mental hospitals-the broken-down failures in this line of personality ! The majority of them escape general notice and detection and are out in the world, causing a great deal of family and social disturbance. I venture to say that they are a greater danger to world peace than any other type of mental 
abnormality. The earlier they are tracked down the better.

But the 'paranoid tendency', which is not identical with paranoia, is still more widespread, and may appear in everyone at some time or other, manifesting itself unmistakably under some particular mental stimulus or provocation. I mean by the paranoid tendency a general disposition to misjudge people, to become suspicious without adequate grounds, to feel that people are working against one when they are not really doing so. The main psychological mechanism involved is that of projection-a projection of the person's aggressiveness and hostility upon others. The tendency is to be explained by the fact that the individual does not fully understand himself and has inadequate control of his excessive aggressiveness.

A person suffering from paranoia, as distinct from the more general paranoid tendency, is usually of a very aggressive temperament, and because of that, his libido has a very rough passage in his mental development. Usually he does not 'get on with' the other sex. The homosexual constituent in his libido is more pronounced than the heterosexual. His aggressiveness also is linked up with feelings towards his own sex, with homosexual tendencies which have been repressed instead of being adequately sublimated. The homosexuality is not admitted by the person concerned; it is rejected and denied. Under repression, the love is actually turned to hate in the unconscious. This hate is then 'projected' upon the other person. $\mathrm{He}$ believes that this other person hates him and therefore persecutes him. The person whom he was ready to love but would not allow himself to love becomes in imagination his persecutor.

Thus the development of persecution mania begins. It is one stage in the development of the average paranoiac. But he may go further and for two alternative reasons develop megalomania. The ordinary explanation of the development of megalomania is that the individual supposes himself persecuted and then asks himself, "Why are all these people against me ?" $\mathrm{H}_{\Theta}$ comes to the conclusion that he must be a very important person if all these others find it necessary to combine against him in this way. He may go so far in his vision of himself as to consider that he is a kind of Messiah, with a special mission.

The other alternative is Freud's explanation, that the libido in such a case is withdrawn altogether from the outer world, and fixed upon the self or ego, thus narcissistically inflating the ego, and producing a regression to infantile narcissism. Megalomania, in Freud's view, is of an infantile nature, and represents a regression or step back from sublimated homosexuality to the infantile stage of narcissism, or fixation of libido upon the ego*.

Thus we have the two fundamental characteristics of full-blown paranoia: persecution mania ( $V e r-$ folgungswahn), and megalomania (Grössenwahn). Paranoia is well defined in Kraepelin's words as "the insidious development, following from inner causes, of a lasting unshakable delusional system (Wahnsystem), which proceeds with complete preservation of clearness in thinking, willing and acting".

But the paranoid tendency is of much wider incidence, revealing itself in relatively normal individuals in special mental situations, with wrongful imputing of motives and misunderstanding of inten-

* Sigmund Freud, “Collected Papers”, 3, 449-452 (Hogarth Press, 1925). tions, so that such people are unnecessarily suspicious and 'on the defensive', taking offence where none is intended and "fleeing where none pursueth". The tendency is linked up with aggressiveness and possibly with the (incompletely sublimated) homosexual constituent of the libido, and with a distorted development of the super-ego through the processes of introjection and projection which occur in the young child's mind in relation to parents, nurses, etc.

\section{The Situation in Germany}

This discussion has an important bearing on the psychological situation in Germany to-day. Many people are content to sum up the problem from the psychological side by saying simply and baldly, "Germany has an inferiority complex", "Hitler had an inferiority complex". No doubt both leader and nation had inferiority complexes in full measure, but these superficial distortions of their minds are not adequate to explain their outrageous behaviour in the last few years. It is something deeper than an inferiority complex which is concerned in the German problem, namely, a paranoid tendency. I have always said that Hitler was a paranoid personality. He was already suffering from some degree of persecution mania and megalomania in the days of his rise to power. The state of his mind was very characteristically shown in his reactions to the Jewish problem in Vienna, as described in Chapter 2 of "Mein Kampf". Hitler's reactions to Jewry and to Bolshevism were paranoid reactions. The line he took, that "terror must be met by terror", is the attitude of the paranoid personality. He was always in a state of defence, arming himself against what must have been at first an imaginary situation, however real it may have become later on owing to his own acts.

No one can be paranoid who fully understands himself. Hitler did not understand himself. To himself he was a knight in shining armour; and the people of Germany, after long-continued disappointment and frustration, came to accept him at his own valuation, especially when he received the support of the military and of 'big business'. The nation had lost its way, and here it found someone who seemed to believe in himself, and accordingly it came to believe in him. The paranoid person, on the surface, does believe in himself; so, for that matter, does the real Messiah, but Hitler was a false and not a real Messiah*.

The people rallied to him, step by step-I need not go into the history of the rise of National Socialism in Germany. He collected around him a number of paranoid individuals, or at any rate psychopathic personalities. The Nazi leaders seem all to be, or to have been, more or less abnormal.

\section{Spread of the Paranoid Tendency}

The psychological consequences of all this in the development of the German nation are clear. The people had become desperate and had lost their way. They were encouraged to be aggressive because they were told, and believed, that they were encircled again, and that others wanted to wipe them out. That was the very simple propaganda repeated by Goebbels on every occasion. "This war which was forced upon us. ..." Goebbels revealed himself most clearly as a classic example of 'acquired paranoia'

* Hitler was also hysterical, and suffered from hysterical blindness at the end of the War of 1914-18 (see "Mein Kampf", p. 223 in the German edition). 
(if one may coin such a phrase) in some of his weekly articles in the Nazi publication, Das Reich. In the literal sense, of course, paranoia cannot be acquired; it is inborn in the individual, but it can take a collective form which is acquired in the group. It has been pointed out by psychologists that as soon as a group is formed the paranoid tendency may spring up as a collective characteristic*. It seems to be a fundamental tendency in group psychology. One group may become paranoid in relation to another. Groups of all kinds link up or develop hostilities towards one another; and if their members are put into uniform the paranoid tendency is magnified.

Germany is going to be one of the great political and psychological problems of the next generation. It is a problem which will require to be dealt with in

*H. Schulte: "Versuch einer Theorie der paranoischen Eigenbeziehung und Wahnbildung", Psych. Forsch., 5 (1924). a strictly scientific way, by the accumulation of facts, not of phantasies or rumours, and the arrangement of such facts in relation to possible hypotheses, which must be tested and confirmed. To this problem some Germans themselves will make valuable contributions. It will be a problem for us all for a generation, for it cannot be left unsolved. We cannot leave a political vacuum in the middle of Europe.

The above essay was written before the cessation of hostilities. But now that Germany and Japan have been completely defeated and the atomic bomb has been invented and used, national mentality and the group mind are in need of understanding and control as never before. It is easier for an atom bomb to wipe out a city than a mental complex. The sciences of psychology, sociology and politics must not fall too far behind the physical sciences in their future development, if ultimate disaster is to be avoided.

\section{NEWS and VIEWS}

\section{New Sibthorpian Professor at Oxford: Mr. G. E. Blackman}

Mr. Geoffrey Blackman, son of Prof. V. H. Blackman, goes to Oxford next term as Sibthorpian professor of rural economy. He succeeds Prof. J. A. Scott Watson, who last year joined the Ministry of Agriculture as chief education and advisory officer. Mr. Blackman was educated at King's College School, and at Cambridge (St. John's) where he took both parts of the Natural Sciences Tripos. After a year of postgraduate work in the Soil Physics Department at Rothamsted, he took up, in 1927, the headship of the Botany Section of the Jealott's Hill Research Station, Berkshire, then newly established by Imperial Chemical Industries, Ltd. In one sense his researches during his eight years tenure of the post were directed to practical ends, such as the improvement of pasture by various combinations of fertilizer and grazing treatments, and the use of various chemicals in the control of weeds. But he contributed materially to the application of modern statistical methods to the botanical analysis of pastures and, what was more important from the long-term point of view, played his part, along with the Aberystwyth workers and others, in developing the ecological approach to grassland problems and to those of weed-crop competition.

Since 1935, Mr. Blackman has been lecturer in plant ecology at the Imperial College, London. $\mathrm{He}$ was also, for three years before the War, assistant science editor of the Gardeners' Chronicle and, since 1942, has been honorary secretary of Biology War Committee. Also, since 1941, he has headed a team of workers, under the Agricultural Research Council, who have been engaged on two major projects. One is the introduction from overseas of improved varieties of oil seeds (sunflower, soya bean and linseed) and maize. This work is still in progress, but has already shown that certain North American linseeds are greatly superior to the mixed La Plata type previously grown; that sunflower seed of good quality can be produced in Britain ; and that certain of the new hybrid types of maize, from the northern United States and Canada, have great promise as forage crops, and especially as silage crops, in southern England. The other project has been a continuation of the long search for more effective and more highly selective herbicides. The practical results already achieved are very important. For example, sulphuric acid, in appropriate concentration, has almost eliminated the laborious process of weeding onion crops; copper nitrate, copper chloride and the sodium salt of di-nitro-ortho-cresol can be safely and effectively used on flax. Sulphuric acid, applied before the emergence of crop seedlings, is of great value in the case of crops such as carrots and beet which, on account of their slow initial growth, are specially liable to be smothered by quick-growing annuals. But most remarkable has been the discovery that certain plant-growth substances, applied at rates of the order of a pound per acre, completely destroy certain species and leave others quite unharmed. One of these materials (C.L.C.), which will soon be available in quantity, is very strongly toxic to a large number of dicotyledonous plants, and harmless to cereals and most other monocotyledons. It is to be hoped that Mr. Blackman will find at Oxford time and facilities to continue this extremely profitable line of work.

\section{Advisory Committee on Atomic Energy}

Is reply to several questions asked in the House of Commons, the Prime Minister has stated that many questions involved in the future of atomic energy, including that of the international handling of the subject and its possible development for industrial purposes, are engaging the attention of the Government. To assist the Government in dealing with the far-reaching questions raised by the discovery, both as regards its international treatment and its further development in Britain, whether for industrial or military purposes, the Government has appointed the following advisory committee: Sir John Anderson (chairman), Sir Alexander Cadogan, Permanent Under-Secretary of State, Foreign Office; FieldMarshal Sir Alan Brooke, chief of the Imperial General Staff; Sir Alan Barlow, Second Secretary of the Treasury; Sir Edward Appleton, secretary of the Department of Scientific and Industrial Research ; Sir Henry Dale, president of the Royal Society; Prof. P. M. S. Blackett, Langworthy professor of physics in the University of Birmingham ; Sir James Chadwick, professor of physics in the University of Liverpool; and Sir George Thomson, professor of 